\title{
The use of isotope injections in sentinel node biopsy for breast cancer: are the 1 - and 2-day protocols equally effective?
}

\author{
Nazera Dodia', Deena El-Sharief ${ }^{2}$ and Cliona C. Kirwan ${ }^{3 *}$
}

\begin{abstract}
Sentinel lymph nodes are mapped using ${ }^{99 m}$ Technetium, injected on day of surgery (1-day protocol) or day before (2-day protocol). This retrospective cohort study compares efficacy between the two protocols. Histopathology for all unilateral sentinel lymph node biopsies (March 2012-March 2013) in a single centre were reviewed. Number of sentinel lymph nodes, non-sentinel lymph nodes and pathology was compared. 2/270 (0.7\%) in 1-day protocol and $8 / 192(4 \%)$ in 2-day protocol had no sentinel lymph nodes removed $(p=0.02)$. The median (range) number of sentinel lymph nodes removed per patient was $2(0-7)$ and $1(0-11)$ in the 1 - and 2 -day protocols respectively $(p=0.08)$. There was a trend for removing more non-sentinel lymph nodes in 2-day protocol [1-day: 52/270 (19\%); 2-day: $50 / 192(26 \%), p=0.07]$. Using 2-day, sentinel lymph node identification failure rate is higher, although within acceptable rates. The 1 and 2 day protocols are both effective, therefore choice of protocol should be driven by patient convenience and hospital efficiency. However, this study raises the possibility that 1-day may be preferable when higher sentinel lymph node count is beneficial, for example following neoadjuvant chemotherapy.
\end{abstract}

Keywords: Sentinel lymph node biopsy, Breast cancer, Isotope, Surgery

\section{Background}

Over the last decade sentinel lymph node biopsy (SLNB) has become the accepted method for staging of the axilla in patients with breast cancer and clinically node negative disease (Giuliano et al. 1994; Veronesi et al. 2003; Mansel et al. 2006).

Although early trials highlight an improved accuracy of SLNB with the removal of multiple nodes (Wong et al. 2001), current evidence shows that in low risk tumours, the dissection of fewer SLNs still achieves an accurate biopsy result (Low and Littlejohn 2006). It is important to establish the optimal number of nodes to be biopsied as an over-dissection can lead to an increased risk of lymphoedema, sensory deficit and impaired shoulder mobility (Mansel et al. 2006). In specific cases, taking more SLNs can be beneficial for example, there is evidence that

\footnotetext{
*Correspondence: cliona.kirwan@manchester.ac.uk

${ }^{3}$ Institute of Cancer Sciences, University of Manchester, University Hospital of South Manchester, Southmoor Road, Wythenshawe, Manchester M23 9LT, UK

Full list of author information is available at the end of the article
}

larger numbers of SLNs reduce the risk of a false negative biopsy result in patients who have undergone neoadjuvant chemotherapy (Boughey et al. 2013; Kuehn et al. 2013).

In the UK, current NICE guidelines (NICE 2009) recommend performing SLNB using the dual technique with isotope and blue dye. Of screen detected invasive breast cancers, $84 \%$ undergo SLNB in the UK (West Midlands NHS Breast Screening Quality assurance Centre 2013).

At our hospital, all women diagnosed with breast cancer and clinically node negative disease (based on axillary ultrasound findings \pm cytology or core biopsy) undergo SLNB. Lymphatic mapping is carried out using the dual technique of ${ }^{99 \mathrm{~m}}$ Technetium isotope and patent blue $\mathrm{V}$.

To increase efficiency the unit has two protocols for SLNB based on when the ${ }^{99 \mathrm{~m}}$ Technetium isotope is injected pre-operatively: the 1-day protocol where the isotope is injected on the day of surgery; and the 2-day protocol where patients are injected the day before. The 1-day protocol is allocated to patients who undergo surgery on the first day of a working week, patients who

\section{望 Springer}


require wire guided tumour localisation prior to surgery or patients who are listed towards the end of the working day. All other patients are usually allocated the 2-day protocol. Previous authors have adopted similar protocols (Winchester et al. 1999; McCarter et al. 2001; Yeung et al. 2001). The 2-day protocol prevents delays to morning lists in a hospital where the isotope is administered in a department geographically separate from the operating theatres and thus increases productivity. Thus these protocols are partly driven by the pragmatics of efficiency for patients and the hospital. To minimise the loss of signal from the isotope an approximately double dose is used in the 2-day protocol, however anecdotally surgeons have reported reduced isotope signal using the 2-day protocol compared to the 1-day protocol.

We hypothesised that (as a result of weakened signal, particularly in secondary and tertiary SLNs) fewer SLNs and more NSLNs would be removed using the 2-day vs 1-day protocol. We aimed to examine whether the any difference in the efficacy of these two techniques could have a clinical impact.

\section{Patients and methods}

This was a single centre, retrospective cohort study of all women with unilateral breast cancer, diagnosed between March 2012 and March 2013, with clinically node negative disease at presentation who required SLNB.

\section{Sentinel lymph node mapping and biopsy technique}

The isotope is prepared off-site and delivered daily to the hospital at 7am and 10.30am. Experienced radiographers administer the isotope intra-dermally into the areola, in the quadrant of the tumour. In the 1-day protocol $20 \mathrm{MBq}$ of $0.1-0.2 \mathrm{ml}{ }^{99 \mathrm{~m}}$ Technetium-labeled sulphur colloid is injected at approximately 9am on the morning of the surgery; in the 2-day protocol $40 \mathrm{MBq}$ of 0.1 $0.2 \mathrm{ml}{ }^{99 \mathrm{~m}}$ Technetium-labeled sulphur colloid is injected at approximately $3 \mathrm{pm}$ the day before surgery. The isotope injection site is localised to the edge of the areola, in the upper outer quadrant of the breast. In addition, $2 \mathrm{ml}$ of $2.5 \%$ patent blue dye is injected after the patient is anaesthetised. The injection is given sub-dermally at the edge of the areola in the upper outer quadrant or in the quadrant of the tumour, depending on the preference of the surgeon. Lymphoscintigrams are not used. Nodes that show radioactivity, using the gamma probe ('hot' nodes), are removed and labelled as SLNs. In addition nodes that are stained blue (with or without radioactivity) are also labelled SLNs. Any non-sentinel lymph nodes (NSLN) removed (e.g. found to contain no signal following removal and no blue staining, or removed as part of a sample in the instance of mapping failure) are labelled as 'non-sentinel nodes'. We aim to remove a maximum of four SLNs, however clinically suspicious nodes may be removed at the surgeon's discretion. All nodes are sent for histological analysis.

\section{Data collection and analysis}

In all patients, the protocol (1- or 2-day), isotope dose, number of SLNs and NSLNs removed, the total number of nodes removed and nodal histology were recorded.

Data was analysed using SPSS version 15. Chi squared, Fisher's exact, Mann-Whitney U and Spearman's correlation were used to analyse the data.

\section{Results}

Of 462 patients undergoing SLNB in the 12-month study period, 270 had SLNB using the 1-day protocol and 192 using the 2-day protocol. The mean dose of isotope used was 22.3 [confidence interval (CI) 22.0-22.7 MBq] MBq for the 1-day protocol and 40.4 [CI (39.9-40.9)] MBq for the 2-day protocol.

Ten patients had a failed sentinel node biopsy (no sentinel node and only non-sentinel nodes removed), with $2 / 270(0.7 \%)$ in the 1 -day protocol and $8 / 192(4 \%)$ in the 2 -day protocol $(\mathrm{p}=0.02)$. Of these ten patients, only one patient had lymph node metastases ( 2 of 5 nodes positive, 2-day protocol).

The median total number of nodes per patient was similar between the 1 and 2-day protocols [1-day: $2(0-7)$, 2-day: $2(0-11), p=0.7]$, however there appeared to be a greater number of sentinel nodes removed on the 1-day protocol and non-sentinel nodes on the 2-day protocol.

The median (range) number of SLNs removed per patient was $2(0-6)$ in the 1-day protocol and 1 (range $0-11)$ for the 2-day protocol ( $\mathrm{p}=0.08)$ (Fig. 1).

There was a trend for a higher proportion of patients having one or more NSLNs removed in the 2-day [50/192 $(26 \%)$ than the 1-day protocol $(52 / 270$ [19\%]) $(\mathrm{p}=0.07)$ (Fig. 2).

As expected, there was an inverse correlation between number of SLNs and number of NSLNs removed $(\mathrm{p}=0.002$, Spearman's correlation -0.12$)$.

Lymph node metastases were found in 15 patients (5.5\%; 13 macrometastases, 2 micrometastases) on the 1 -day protocol and 16 patients $(8.3 \%$; 13 macrometastases, 3 micrometastases) on the 2-day protocol. Only one patient had a micrometastasis in a NSLN in the presence of normal SLNs, indicating a falsely negative SLNB, however no further disease was found on completion axillary node clearance. One patient had two macrometastases in NSLNs, with extracapsular spread, without any SLNs being removed, implying a failure of lymphatic mapping, however this was recognised at surgery with the histological sample labelled 'axillary sample.' 


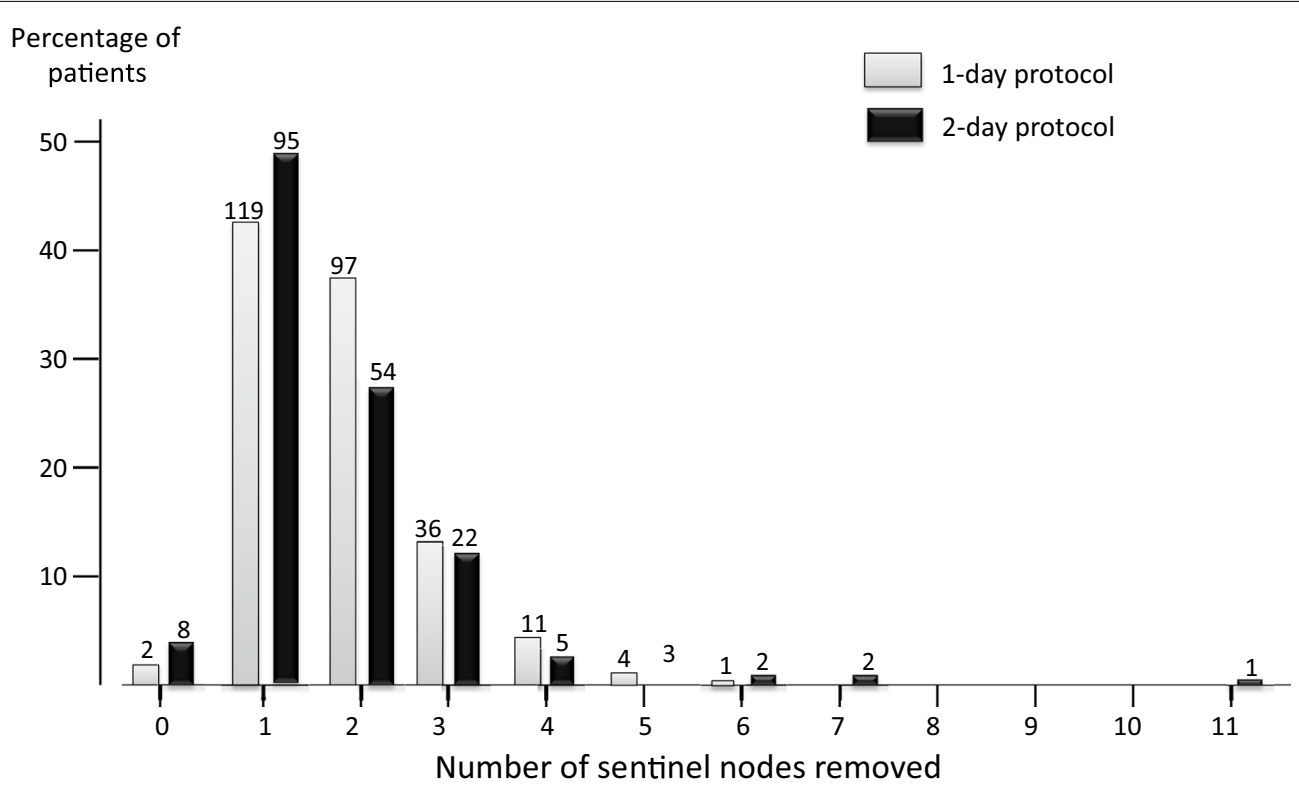

Fig. 1 Percentage of patients with different numbers of sentinel lymph nodes (SLNs) removed at sentinel lymph node biopsy, separated into 1-day ( rey, $\mathrm{n}=270$ ) and 2-day (black, $\mathrm{n}=192$ protocols). The median (range) number of SLNs removed per patient was $2(0-6)$ in the 1-day protocol and $1(0-11)$ for the 2-day protocol $(p=0.08)$. There was a trend for a higher percentage of patients having two or more SNs removed with the 1-day protocol $(55 \%)$ compared with the 2-day protocol $(46 \%)(p=0.06)$. Bar chart is shown as percentage of patients, with absolute numbers given above individual bars

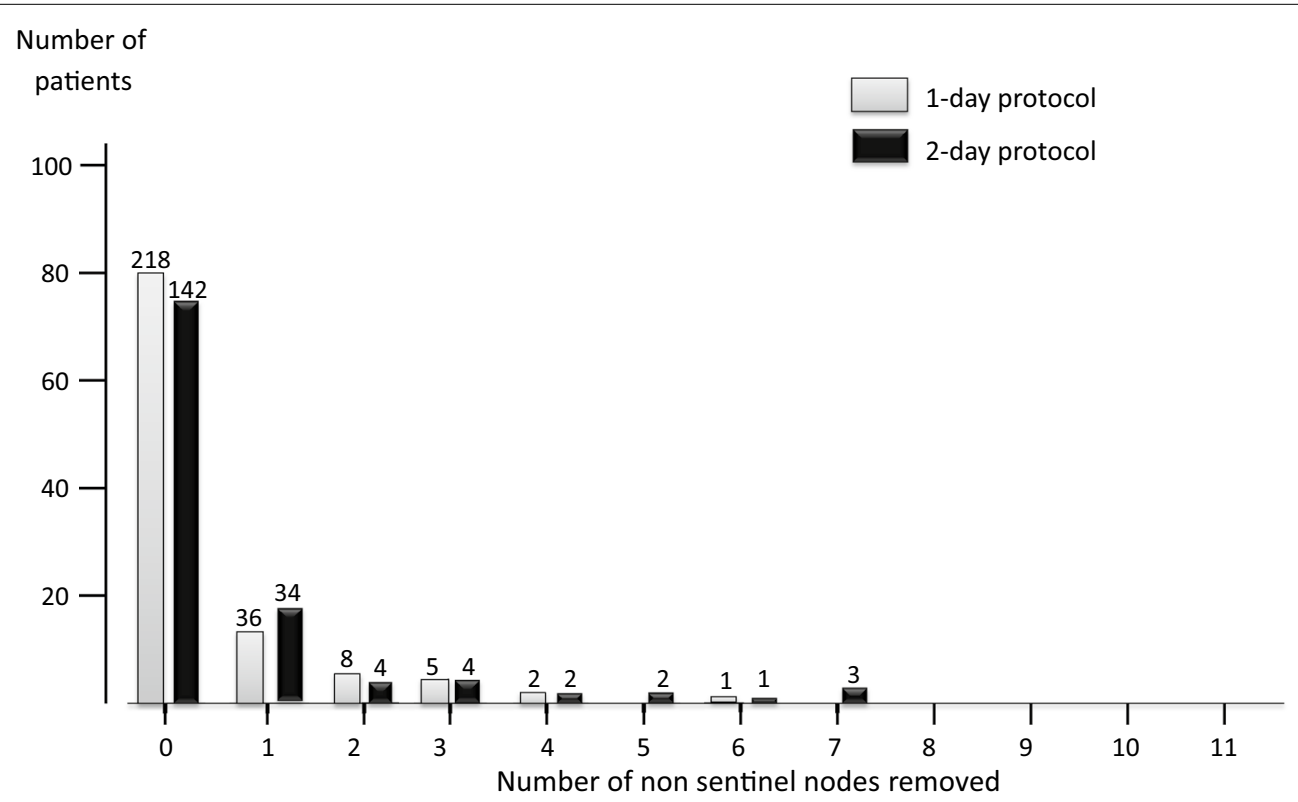

Fig. 2 Percentage of patients with different numbers of non-sentinel lymph nodes (NSLNs) removed at sentinel lymph node biopsy, separated into 1-day ( grey, $\mathrm{n}=270$ ) and 2-day (black, $\mathrm{n}=192$ ) protocols. There was a trend for a higher proportion of patients having one or more NSLN removed in the 2-day protocol (1-day: 52/270 (19\%); 2-day: 50/192 (26\%), $\mathrm{p}=0.07)$. Bar chart is shown as percentage of patients, with absolute numbers given above individual bars 


\section{Discussion}

This study compares the 1- and 2-day protocols for sentinel node biopsy. It aimed to determine whether there was any clinically relevant difference in the two techniques, where choice of technique is largely driven by pragmatics and efficiency.

There is an increased rate of failure of sentinel node technique using the 2-day protocol compared with the 1-day protocol. In published literature, the failure rate of identifying the sentinel node is $2-8 \%$ (Veronesi et al. 1997; Giuliano et al. 1997; Albertini et al. 1996; Krag et al. 1998). Using the combined blue dye and isotope techniques, UK and American guidelines for surgeons new to SLNB recommend a maximum rate of 10 and $15 \%$ false negative respectively, before using the SLNB technique independently (Association of Breast Surgery at B 2009; Simmons 2001). Although the 2-day protocol failure rate in our study is statistically significantly higher, whether this is clinically significant is questionable given that at $4 \%$, the failure rate is still within the clinically acceptable level.

Surgeons anecdotally report that 1-day protocols can result in a relatively 'noisy' axilla. We hypothesised that secondary and tertiary sentinel nodes may have a detectable signal with the 'noisy' one-day protocol, but become undetectable with the less 'noisy' 2-day protocol.

This is supported by our finding of a trend for greater number of SLNs being removed with the 1-day protocol. It is possible that surgeons were removing many hot nodes before finding the hottest node. The NEW START programme defines SLNs as any nodes with $>10 \%$ of the count of the node with the maximum count rate. In this current study we do not have the count rates of the SLNs removed so cannot verify if they are true SLNs as defined by NEW START (MacNeill et al. 2005). In addition, some of our SLNs may have been 'blue' and not 'hot', however it is recognised that only $5 \%$ of identified SLNs are 'blue' and not 'hot', so this is unlikely to have a significant impact on our findings (Krag et al. 2007).

Our study provides a potential argument for using a 1-day protocol in selected patients where the sensitivity of SLNB is questioned and may be improved by a higher yield of SLNs, for example, following neoadjuvant chemotherapy (Boughey et al. 2013; Kuehn et al. 2013). In patients receiving neoadjuvant chemotherapy for clinically node negative disease, some authors report a higher false negative rate of SLNB when performed after chemotherapy than prior to chemotherapy (Papa et al. 2008; Kang et al. 2004). In biopsy proven node positive patients undergoing SLNB following neoadjuvant chemotherapy in the ACOSOG Z1071 Trial, the false negative rate was $10 \%$ or less as long as a minimum of 2 SLNs were removed (Boughey et al. 2013). In our current study, there was a trend for a higher percentage of patients having two or more SLNs removed with the 1-day protocol (55\%) compared with the 2-day protocol (46\%) $(\mathrm{p}=0.06)$, highlighting that the 1 -day protocol may be beneficial in this subset of patients, through a possible increase in SLN yield, however this is clearly hypothesis generating.

Unlike previous studies, here we also report rates of NSLNs removed. The high percentage of NSLNs taken with the 2-day protocol may reflect difficulty in identifying the SLN. Anecdotally surgeons report 'less noise' in the axilla in the 2-day protocol, suggesting that there is greater signal fade with the 2-day protocol, despite a double dose of isotope. This would result in a quieter signal in SLNs, making them harder to find. This hypothesis is supported by our current data, with a trend for higher number of SLNs removed with the 1-day protocol compared with the 2-day protocol and more NSLNs found in the 2-day protocol. With increased difficulty in locating SLNs (due to weaker signal) the surgeon may take NSLNs anatomically close to the SLN by mistake if they are easily palpable, or have to resort to an axillary node sample. This is further supported by the inverse correlation between number of sentinel nodes and non-sentinel nodes removed. It is interesting that previous studies comparing 1- and 2-day protocols have not commented on rates of NSLN removal. Our findings are at odds with McCarter et al., who found that more SLNs were found on lymphoscintigraphy on the 2-day protocol (McCarter et al. 2001). It is likely that their study contradicts ours because the isotope dose was increased by five between their 1- and 2-day protocols, which may further support the hypothesis above that protocol technique can be adapted to increase the SLN yield in situations where this is beneficial (e.g. post neoadjuvant chemotherapy). In our current study, despite ${ }^{99 \mathrm{~m}}$ Technetium having a relatively short half-life of only $6 \mathrm{~h}$, and a relatively smaller dose used compared to the previous study, the 2-day signal was sufficient for successful SLNB in $96 \%$ of patients.

In this current series, removal of NSLNs added no additional histological information in all but two cases (of which one was a recognised failed SLNB). Removing more NSLNs may suggest a less directed SLNB has been performed, which could potentially increase the risk of morbidity, through additional axillary dissection.

It needs to be acknowledged that in this current cohort study, 1-day patients are a different clinical group to 2-day patients. The 1-day protocol is largely used for patients who need wire localization of a small lesion, whereas 2-day patients usually require ultrasound localisation of a mass lesion, or have clinically palpable lesions requiring no localisation or are undergoing mastectomy. This retrospective study therefore has a clear selection bias with 
2-day patients tending to have larger tumours and more advanced disease. The difference in failure rate may possibly be related to axillary disease as well as technical failure, although node-positivity rate was not significantly higher in the 2-day protocol, despite the presumed selection bias. It is noteworthy that only one of the ten failed SLNB patients had metastases in their NSLNs. It is possible, however, that more NSLNs could be deliberately biopsied in the 2-day protocol due to more clinical concern.

A limitation of this study is that our data did not include details of time from injection to surgery. Potentially some patients on the 1-day protocol could have had surgery up to $8 \mathrm{~h}$ after injection, and patients on the 2-day protocol, had surgery only $16 \mathrm{~h}$ after injection, blurring the boundaries between these two groups.

\section{Conclusions}

This study highlights that the 2-day protocol has a higher failure rate and may make identifying SLNs more challenging, with resultant increased NSLN removal, and therefore potentially greater axillary dissection. However the true clinical significance of this is likely to be small. Here we have demonstrated that both the 1- and 2-day protocols are clinically safe and largely equivalent. Choice of protocol should be driven by patient convenience and hospital efficiency. However, considering the potentially higher SLN yield achieved with the 1-day protocol, we hypothesise that the 1-day protocol is preferential in the subset of patients where a high SLN yield may influence clinical management, for example following neoadjuvant chemotherapy.

\section{Abbreviations \\ SLNB: sentinel lymph node biopsy; SLN: sentinel lymph node; NSLN: non- sentinel lymph node.}

\section{Authors' contributions}

ND performed data acquisition and analysis and helped draft the manuscript. DES participated in interpretion of results and drafting of the manuscript. CCK designed the project, helped analyse results and participated in and coordinated the drafting of the manuscript. All authors read and approved the final manuscript.

\section{Author details \\ ${ }^{1}$ Manchester Medical School, University of Manchester, Stopford Building, Oxford Rd, Manchester M13 9PT, UK. ${ }^{2}$ Department of Breast Surgery, University Hospital of South Manchester, Southmoor Road, Wythenshawe, Manchester M23 9LT, UK. ${ }^{3}$ Institute of Cancer Sciences, University of Manches- ter, University Hospital of South Manchester, Southmoor Road, Wythenshawe, Manchester M23 9LT, UK}

\section{Compliance with ethical guidelines}

\section{Competing interests}

The authors declare that they have no competing interests.

\section{Funding}

No funding was required for this research project.
Received: 12 August 2015 Accepted: 7 September 2015

Published online: 15 September 2015

\section{References}

Albertini JJ, Lyman GH, Cox C, Yeatman T, Balducci L, Ku N, Shivers S, Berman C, Wells K, Rapaport D, Shons A, Horton J, Greenberg H, Nicosia S, Clark R, Cantor A, Reintgen DS (1996) Lymphatic mapping and sentinel node biopsy in the patient with breast cancer. JAMA 276:1818-1822

Association of Breast Surgery at B (2009) Surgical guidelines for the management of breast cancer. Eur J Surg Oncol 35(Suppl 1):1-22. doi:10.1016/j. ejso.2009.01.008

Boughey JC, Suman VJ, Mittendorf EA, Ahrendt GM, Wilke LG, Taback B, Leitch AM, Kuerer HM, Bowling M, Flippo-Morton TS, Byrd DR, Ollila DW, Julian TB, McLaughlin SA, McCall L, Symmans WF, Le-Petross HT, Haffty BG, Buchholz TA, Nelson H, Hunt KK, Alliance for Clinical Trials in O (2013) Sentinel lymph node surgery after neoadjuvant chemotherapy in patients with node-positive breast cancer: the ACOSOG Z1071 (Alliance) clinical trial. JAMA 310:1455-1461. doi:10.1001/jama.2013.278932

Giuliano AE, Kirgan DM, Guenther JM, Morton DL (1994) Lymphatic mapping and sentinel lymphadenectomy for breast cancer. Ann Surg 220:391-398 (discussion 8-401)

Giuliano AE, Jones RC, Brennan M, Statman R (1997) Sentinel lymphadenectomy in breast cancer. J Clin Oncol 15:2345-2350

Kang SH, Kim SK, Kwon Y, Kang HS, Kang JH, Ro J, Lee ES (2004) Decreased identification rate of sentinel lymph node after neoadjuvant chemotherapy. World J Surg 28:1019-1024. doi:10.1007/s00268-004-7367-7

Krag D, Weaver D, Ashikaga T, Moffat F, Klimberg VS, Shriver C, Feldman S, Kusminsky R, Gadd M, Kuhn J, Harlow S, Beitsch P (1998) The sentinel node in breast cancer — a multicenter validation study. N Engl J Med 339:941-946. doi:10.1056/NEJM199810013391401

Krag DN, Anderson SJ, Julian TB, Brown AM, Harlow SP, Ashikaga T, Weaver DL, Miller BJ, Jalovec LM, Frazier TG, Noyes RD, Robidoux A, Scarth HM, Mammolito DM, McCready DR, Mamounas EP, Costantino JP, Wolmark N, National Surgical Adjuvant B, Bowel P (2007) Technical outcomes of sentinel-lymph-node resection and conventional axillary-lymph-node dissection in patients with clinically node-negative breast cancer: results from the NSABP B-32 randomised phase III trial. Lancet Oncol 8:881-888. doi:10.1016/S1470-2045(07)70278-4

Kuehn T, Bauerfeind I, Fehm T, Fleige B, Hausschild M, Helms G, Lebeau A, Liedtke C, von Minckwitz G, Nekljudova V, Schmatloch S, Schrenk P, Staebler A, Untch M (2013) Sentinel-lymph-node biopsy in patients with breast cancer before and after neoadjuvant chemotherapy (SENTINA): a prospective, multicentre cohort study. Lancet Oncol 14:609-618. doi:10.1016/S1470-2045(13)70166-9

Low KS, Littlejohn DR (2006) Optimal number of sentinel nodes after intradermal injection isotope and blue dye. ANZ J Surg 76:472-475. doi:10.1111/j.1445-2197.2006.03752.x

MacNeill F, Mansel R, Purushotham A, Clarke D, West N, Frier M, Ell P, Waddington W, Ebdon-Jackson S, Perkins A, Bobrow L, Pinder S, Britten A, Monypenny I, Goyal A, Giuliano A, Horgan K, Townson J, Morton R, Peet D, Horton P, Keshtgar M (2005) NEW START—sentinel lymph node biopsy handbook. Royal College of Surgeons e-book

Mansel RE, Fallowfield L, Kissin M, Goyal A, Newcombe RG, Dixon JM, Yiangou C, Horgan K, Bundred N, Monypenny I, England D, Sibbering M, Abdullah TI, Barr L, Chetty U, Sinnett DH, Fleissig A, Clarke D, Ell PJ (2006) Randomized multicenter trial of sentinel node biopsy versus standard axillary treatment in operable breast cancer: the ALMANAC Trial. J Natl Cancer Inst 98:599-609. doi:10.1093/jnci/djj158

McCarter MD, Yeung H, Yeh S, Fey J, Borgen PI, Cody HS 3rd (2001) Localization of the sentinel node in breast cancer: identical results with same-day and day-before isotope injection. Ann Surg Oncol 8:682-686

NICE (National Institute for Health and Care Excellence) (2009) Early and locally advanced breast cancer:diagnosis and treatment. NICE guidelines CG80. http://www.nice.org.uk/guidance/cg80

Papa MZ, Zippel D, Kaufman B, Shimon-Paluch S, Yosepovich A, Oberman B, Sadetzki S (2008) Timing of sentinel lymph node biopsy in patients receiving neoadjuvant chemotherapy for breast cancer. J Surg Oncol 98:403-406. doi:10.1002/jso.21128 
Simmons RM (2001) Review of sentinel lymph node credentialing: how many cases are enough? J Am Coll Surg 193:206-209

Veronesi U, Paganelli G, Galimberti V, Viale G, Zurrida S, Bedoni M, Costa A, de Cicco C, Geraghty JG, Luini A, Sacchini V, Veronesi P (1997)

Sentinel-node biopsy to avoid axillary dissection in breast cancer with clinically negative lymph-nodes. Lancet 349:1864-1867. doi:10.1016/ S0140-6736(97)01004-0

Veronesi U, Paganelli G, Viale G, Luini A, Zurrida S, Galimberti V, Intra M, Veronesi P, Robertson C, Maisonneuve P, Renne G, De Cicco C, De Lucia F, Gennari R (2003) A randomized comparison of sentinel-node biopsy with routine axillary dissection in breast cancer. N Engl J Med 349:546-553. doi:10.1056/NEJMoa012782

West Midlands NHS Breast Screening Quality assurance Centre (2013) An audit of screen-detected breast cancers for the year of screening April 2011 to March 2012. Public Health England Publications. 87
Winchester DJ, Sener SF, Winchester DP, Perlman RM, Goldschmidt RA, Motykie G, Martz CH, Rabbitt SL, Brenin D, Stull MA, Moulthrop JM (1999) Sentinel lymphadenectomy for breast cancer: experience with 180 consecutive patients: efficacy of filtered technetium 99m sulphur colloid with overnight migration time. J Am Coll Surg 188:597-603

Wong SL, Edwards MJ, Chao C, Tuttle TM, Noyes RD, Carlson DJ, Cerrito PB, McMasters KM (2001) Sentinel lymph node biopsy for breast cancer: impact of the number of sentinel nodes removed on the false-negative rate. J Am Coll Surg 192:684-689 (discussion 9-91)

Yeung HW, Cody IH, Turlakow A, Riedel ER, Fey J, Gonen M, Nunez R, Yeh SD, Larson SM (2001) Lymphoscintigraphy and sentinel node localization in breast cancer patients: a comparison between 1-day and 2-day protocols. J Nucl Med Off Publ Soc Nucl Med 42:420-423

\section{Submit your manuscript to a SpringerOpen ${ }^{\circ}$ journal and benefit from:}

- Convenient online submission

- Rigorous peer review

- Immediate publication on acceptance

- Open access: articles freely available online

- High visibility within the field

- Retaining the copyright to your article

Submit your next manuscript at $\boldsymbol{\wedge}$ springeropen.com 